\title{
POLÍTICAS DE TRADUÇÃO: UM TEMA DE POLÍTICAS LINGUÍSTICAS?
}

\section{POLÍTICAS DE TRADUCCIÓN: ¿UN TEMA DE POLÍTICAS LINGÜÍSTICAS?}

\author{
TRANSLATION POLICIES: A THEME OF LINGUISTIC POLICIES?
}

\author{
Silvana Aguiar dos Santos* \\ Universidade Federal de Santa Catarina \\ Camila Francisco** \\ Universidade do Vale do Itajaí
}

\begin{abstract}
RESUMO: Neste ensaio, parte-se do pressuposto de que a falta de articulação entre políticas de tradução e políticas linguísticas torna invisíveis algumas iniciativas realizadas em nosso país. A proposta é apresentar e dialogar de forma sucinta com diferentes elementos que atravessam os processos tradutórios e interpretativos e que constituem temas de interesse das políticas de tradução. Para essa reflexão, recuperam-se as contribuições de Baker (2006a, 2006b), Tymoczko (2007) e Panda (2013), as quais apresentam reflexões sobre a tradução e a interpretação, o papel que elas desempenham e as políticas adotadas por diversos governos. A partir deste debate, sugerimos um diálogo articulado entre políticas de tradução e políticas linguísticas. Consideramos que esta conexão pode ser um caminho para compreender que toda ação em torno da língua, seja ela econômica, social, cultural ou linguística, gera efeitos de cunho tradutório.
\end{abstract}

PALAVRAS-CHAVE: Políticas de tradução. Políticas linguísticas. Tradução-interpretação.

RESUMEN: Este ensayo parte de la premisa de que la falta de articulación entre políticas de traducción y políticas lingüísticas que no dan visibilidad a algunas iniciativas realizadas en nuestro país. La propuesta es presentar y dialogar de forma sucinta con diferentes elementos que atraviesan los procesos de traducción e interpretativos y que constituyen temas de interés de las políticas de traducción. Para esta reflexión, se recuperan las contribuciones de Baker (2006a, 2006b), Tymoczko (2007) y Panda (2013), las cuales presentan reflexiones acerca de la traducción y la interpretación, el papel que desempeñan y las políticas adoptadas por diversos gobiernos. A partir de este debate, sugerimos un diálogo articulado entre políticas de traducción y políticas lingüísticas. Consideramos que esta conexión puede ser un camino para comprender que toda acción que involucra la lengua, sea económica, social, cultural o lingüística, genera efectos en la traducción.

PALABRAS CLAVE: Políticas de traducción. Políticas lingüísticas. Traducción-interpretación.

ABSTRACT: In this essay, it is assumed the lack of articulation between translation policies and linguistic policies makes some initiatives conducted in our country invisible. The purpose of this essay is to present and briefly dialogue with different elements that traverse translation and interpretative processes and which constitute topics of interest for translation policies. For this

\footnotetext{
* Professora colaboradora do Programa de Pós-Graduação em Estudos da Tradução da Universidade Federal do Ceará e Professora no Departamento de Língua de Sinais Brasileira - DLSB da Universidade Federal de Santa Catarina. Vicelíder do Grupo de Pesquisa em Interpretação e Tradução de Línguas de Sinais - InterTrads. Membrodo Grupo de Pesquisa Políticas Linguísticas Críticas.E-mail:s.santos@ufsc.br.

** Bacharel em Letras-Libras pela Universidade Federal de Santa Catarina. Especialização (em andamento) pelo Instituto Federal Catarinense - IFC na linha Processos Educativos e Inclusão. Tradutora e Intérprete de Libras-Português da UniversidadedoValedo Itajaí - Univali. E-mail: camilallufsc@gmail.com.
} 
reflection, the contributions of Baker (2006a, 2006b), Tymoczko (2007) and Panda (2013) are presented, with discussions on translation and interpretation, their roles and the policies adopted by different governments. From this debate, an articulated dialogue between translation policies and language policies is suggested. We consider this connection can be a pathway to understand that any action around the language, whether economic, social, cultural or linguistic, generates translation effects KEYWORDS: Translation policies. Linguistic policies. Translation-interpretation.

\section{INTRODUÇÃO}

Neste ensaio, realizamos uma reflexão pautada na conexão entre o campo das políticas de tradução e o das políticas linguísticas ${ }^{1}$. No âmbito internacional, o campo das políticas de tradução emerge com frequência nos discursos e nas produções acadêmicas aliado ao campo dos Estudos da Tradução. Na Universidade do Cairo, por exemplo, há um programa de mestrado sobre políticas de tradução cuja visão fundamenta-se em estabelecer uma perspectiva cultural a partir das realidades das universidades egípcias. Ou seja, o programa compromete-se a discutir e colocar em cena as demandas dos tradutores e do público envolvido diretamente com a tradução naquele país.

Um exemplo disso é o enfoque dado às editoras, pois elas lidam diretamente com os projetos de tradução lançados no mercado, o que pode impactar na circulação de determinadas obras em detrimento de outras. Essas escolhas das editoras sobre o quê, como e em que lugar as traduções irão circular não são isentas de influências sociais, econômicas, políticas e culturais. Quando um programa de pós-graduação se propõe a ampliar as pesquisas e os debates sobre tradução, considerando o processo de traduzir e o produto final, isto é, a tradução propriamente dita para além do âmbito acadêmico, as mudanças podem ser várias.

Uma delas refere-se à forma de conceber o ato tradutório como uma "atividade consciente" do papel que o tradutor desempenha em um determinado projeto de tradução. Ou seja, é importante que esse profissional não encare a operação textual ou interpretativa (nos casos de interpretação simultânea ou consecutiva) por si só, mas considere que esses materiais e comunidades envolvidas carregam consigo aspectos culturais e políticos cruciais para uma nação. Desta forma, o ato de traduzir ou interpretar está diretamente articulado com questões sociais, econômicas, culturais, entre outras.

A relação de aspectos culturais e traduções, por exemplo, tem sido investigada com maior intensidade no âmbito acadêmico a partir de diferentes perspectivas. Uma dessas perspectivas é a da diversidade cultural e de sua celebração por meio das traduções, meio que permite atravessar rios e oceanos para promover línguas, culturas e povos. Outro ponto de vista sobre tradução e aspectos culturais coloca em jogo a noção de diferença, de singularidade para cada prática a ser traduzida, questão central para Bhabha (2005, p. 230):

\footnotetext{
Na irrequieta pulsão de tradução cultural, lugares híbridos de sentido abrem uma clivagem na linguagem da cultura que sugere que a semelhança do símbolo, ao atravessar os locais culturais, não deve obscurecer o fato de que a repetição do signo é, em cada prática social e específica, ao mesmo tempo diferente e diferencial. [...] a "estrangeiridade" da língua é o núcleo do intraduzível que vai além da transferência do conteúdo entre textos ou práticas culturais.
}

Assim como afirma o autor, cabe ao tradutor (acrescentamos também ao intérprete) perceber-se nesse movimento de fluidez, de constante movimento, de deslocamento, de ocupar o entre-lugar tão presente nas fronteiras culturais. Ou seja, espera-se do profissional, nos casos da tradução cultural, um grau de intervenção bastante acentuado, inclusive ciente de que suas escolhas lexicais, terminológicas e culturais podem afetar os processos de visibilização ou de apagamento de certos povos. As expectativas, $O$ grau de intervenção e a liberdade de que os tradutores podem desfrutar, especialmente em textos literários, nem sempre são concedidos a outros tipos de textos. Por exemplo, ao considerar textos jurídicos, o grau de intervenção criativo, as estratégias empregadas e as escolhas adotadas pelo tradutor seguem a rigidez dos sistemas legais.

\footnotetext{
${ }^{1}$ Agradecemos as contribuições das professoras Cristine Görski Severo e Aline Nunes de Sousa pelos comentários críticos, discussões e trocas de ideias que auxiliaram na construção deste material, assim como, as traduções realizadas do inglês-português por Elisângela Liberati e as traduções do espanhol por Noemi Teles de Melo.
} 
O fato de existir essa austeridade exacerbada com os textos que pertencem ao contexto jurídico, e que por consequência afetam o processo de tradução, não quer dizer que em alguns setores do Judiciário, e até mesmo em âmbito policial, não tenham emergido situações que levaram a discussões e debates sobre as questões culturais. Um exemplo disso pode ser observado na crise migratória em diversas partes do mundo, especialmente na Europa. É difícil pensar que um intérprete, quando solicitado a prestar seus serviços no tribunal ao se deparar com imigrantes de culturas muito distantes, não enfrente tensões socioculturais e linguísticas que podem afetar o processo de interpretação, seja ele simultâneo, intermitente ou consecutivo.

É evidente que a atividade de interpretação diferencia-se da atividade de tradução, pois, ao interpretar em contextos comunitários, o encontro face a face e o discurso em caráter de diálogo são características constituintes da interpretação em contextos públicos, tema já abordado nos Estudos da Interpretação por alguns autores como Wadensjö (1998), Pöchhacker (2004), Rodrigues (2010), Queiroz (2011), Jesus (2013). As razões apresentadas até o momento explicitam que o termo "políticas de tradução" engloba uma série de assuntos relevantes a serem discutidos e investigados não só no contexto acadêmico, mas também junto às entidades de classe e demais órgãos representativos dos tradutores. Essas reflexões realizadas até o momento deveriam ser elemento central dos currículos de formação de tradutores e de intérpretes, das pesquisas desenvolvidas junto aos programas de pós-graduação e das políticas linguísticas. Essa empreitada poderia ser um caminho viável para implementar ações governamentais mais incisivas em nosso país sobre políticas de tradução. Tendo feito esta introdução, apresentamos, na próxima seção, considerações iniciais sobre as políticas de tradução.

\section{POLÍTICAS DE TRADUÇÃO: O USO DOS TERMOS “TRADUÇÃO E POLÍTICA” E “POLÍTICAS DE TRADUÇÃO”}

Ao recuperarmos o mapa fundacional dos Estudos da Tradução proposto por Holmes (1972), nota-se que a subárea de políticas de tradução foi contemplada pelo autor. O aspecto prático da atuação dos tradutores, esclarecimentos à sociedade em geral acerca do papel do tradutor, as funções a desempenhar, a defesa de rigorosas e extensas pesquisas sobre a eficácia da tradução como método de ensino de línguas estrangeiras são tópicos descritos por James Holmes para conceituar a área de políticas de tradução.

As subáreas de tradução e política e de políticas de tradução são registradas no mapa proposto pela editora St. Jerome. É possível verificar a existência e a distinção dessas subáreas, o que até então não havia ocorrido nos demais mapeamentos nos Estudos da Tradução. Pode-se observar a expansão dos elementos que caracterizam cada um desses termos, assim como as ações que são tomadas a favor ou contra nessas subáreas.

Com base nesses mapas, ressaltamos que o termo "tradução e política" estaria associado às questões que interessam ao tradutor e à tradução propriamente dita, compreendendo desde o ensino de línguas para tradutores até o assessoramento sobre a função do profissional da tradução. Outra circunstância que exemplificaria o termo "tradução e política" são elementos que constituem contextos políticos marcados por situações de conflito. Um exemplo que ilustra essa questão são os tradutores ou intérpretes que realizam seus trabalhos em meio a fronteiras, zonas de guerra, conflitos étnicos e religiosos.

Tais espaços são marcados por tensões e negociações culturais, linguísticas e religiosas, que, de algum modo, afetam as escolhas tradutórias, além de colocar em risco a vida de tradutores e de intérpretes. Nessas situações que abrangem a atuação do tradutor e do intérprete em zonas de risco, a ideologia de um país ou povo pode sobressair-se de forma bastante radical, deixando marcas acentuadas no texto, no processo de tradução ou de interpretação e, por consequência, na vida profissional daqueles que trabalham nessa empreitada.

Todas essas questões interessam à subárea Tradução e Política, mas são pouco exploradas nas pesquisas acadêmicas desenvolvidas junto aos Estudos da Tradução ou Estudos da Interpretação. Uma das pesquisadoras que recuperou esse tema foi Nascimento (2016), que discute a invisibilidade do intérprete a partir da representação de Abed no livro Notas sobre Gaza: 
O papel do intérprete, tradutor, guia ou "faz tudo", é muitas vezes omitido em zonas de conflito. Dificilmente se vê a representação de tradutores, intérpretes e linguistas em matérias jornalísticas. No entanto, para conseguir transmitir uma notícia, coletar dados, documentos e entrevistar testemunhas, é fundamental contar com a companhia de um intérprete local em contextos de guerra. Com o propósito de melhor exemplificar a importância de mediador linguístico e cultural, um dos muitos papéis que o intérprete assume, escolheu-se o livro Notas sobre Gaza, de Joe Sacco, trabalho relevante nas esferas jornalística, literária e linguística, que traz diversos elementos do ofício de tradutores e intérpretes. A reconstrução de memórias, lembranças e eventos da guerra são coladas e remendadas com a ajuda de Abed, o intérprete de Sacco em sua segunda visita à Gaza (NASCIMENTO, 2016, p. 201).

É inegável que a atuação do intérprete em espaços marcados por guerra ou zonas de conflito carrega consigo traços que estão atrelados às questões políticas. Considerando esse contexto, os tradutores e os intérpretes são duplamente esquecidos e marginalizados no que tange à falta de reconhecimento profissional. Primeiramente, são invisíveis para a esfera jornalística, espaço que se utiliza cotidianamente dos serviços de tradução e de interpretação para cobertura das notícias internacionais e dos conflitos em diversas partes do mundo, segundo Nascimento (2016). Em segundo lugar, os tradutores, nesses espaços de tensão, são marginalizados, expostos a violências física e psicológica e ainda hostilizados pelas comunidades das quais são provenientes. Ou seja, Nascimento (2016) ressalta que essas comunidades não legitimam a atuação desses profissionais por considerarem que são traidores de uma nação. A questão da traição e da falta de valorização são temas abordados em várias pesquisas filiadas aos Estudos da Tradução. Entre esses estudos, podemos citar o trabalho de Nascimento (2016, p.207):

A questão de invisibilidade do tradutor é bastante latente nos Estudos da Tradução e também na esfera jornalística. Entrevistas, dados e fatos raramente são destacados como traduzidos em jornais. No meio televisivo, nota-se a presença da tradução por meio de voice-over e legendas. Porém, quando uma matéria está sendo feita juntamente com um intérprete, a menção a ele ou ao fato de que se trata de uma tradução não aparece.

Há uma linha muito tênue entre visibilidade e invisibilidade. Ao mesmo tempo que a invisibilidade do tradutor e do intérprete é fato em alguns países, em determinadas regiões conflituosas são registrados casos nos quais esses profissionais atuam como agentes ou ainda ativistas da tradução. Esse assunto é bastante discutido por Mona Baker em Translation and Activism (2006), em português “Tradução e Ativismo", e em Translation and Conflict (2006), em português “Tradução e Conflito", e por Tymoczko (2007) no livro Enlarging translation, empowering translators, em português " Expandindo a tradução, empoderando tradutores”. Novamente, os termos "tradução e política" emergem de forma nítida nesses contextos de conflitos culturais, ideológicos e linguísticos, ou ainda, no caso do Brasil, por exemplo, conflitos agrários ${ }^{2}$ e de corrupção ${ }^{3}$. Todos eles marcados por tensões e negociações.

Baker (2006a, 2006b) e Tymoczko (2007) afirmam que os tradutores e os intérpretes lidam diretamente com os aspectos ideológicos, as arenas de conflitos, as questões de dominação e resistência, além dos movimentos políticos que se entrelaçam na atuação do profissional da tradução. Todos esses elementos unem forças para que o empoderamento dos tradutores e intérpretes se torne visível e reconhecido no meio em que atuam profissionalmente. Os elementos discutidos até o momento podem oferecer pistas para melhor compreender os assuntos que constituem a subárea de Tradução e Política conforme apresentado no mapeamento da St. Jerome.

Ainda que tenhamos registro dos termos "tradução e política” e "políticas de tradução" nos mapeamentos de Holmes (1972) e da editora St. Jerome, pesquisas que investigam essas subáreas ou, de algum modo, se afiliam a elas, são incipientes quando tratamos do campo dos Estudos da Tradução. Meylaerts (2010) ressalta, por exemplo, a ausência do termo “políticas de tradução" em várias obras publicadas no campo dos Estudos da Tradução, tais como Munday (2009), Pöchhacker (2004), Pym (2010), Venuti (2000) e a enciclopédia na área de tradução de Baker e Saldanha (2008). De algum modo, todos esses autores poderiam articular os temas

\footnotetext{
${ }^{2}$ No Brasil, o conflito agrário tem ganhado destaque na mídia internacional, especialmente, pelos altos índices dos casos de violência ocorridos nos estados do Pará e de Rondônia nos últimos anos.

${ }^{3}$ Outro exemplo tem sido os casos de corrupção que assolam o país, em especial aqueles investigados pela Operação Lava-Jato. Nessa operação, algumas empresas multinacionais estão envolvidas no caso, o que denota a investigação de alguns países e, por consequência, a necessidade de tradução.
} 
tratados nas obras como parte de uma política da tradução, afinal os contextos de interpretação, a história da interpretação, a profissionalização, os campos de pesquisa e as diferentes abordagens teóricas são temáticas passíveis de articulação à subárea Políticas de Tradução.

Cabe ressaltar que não somente os termos "tradução e política" e "políticas de tradução" foram registrados no campo dos Estudos da Tradução. Embora Meylaerts (2010) tenha destacado a falta do termo "políticas de tradução" nas principais obras da área dos Estudos da Tradução, Schäffner (2007) apresenta e discute o termo "política e tradução". A autora aborda a natureza complexa do discurso da tradução, os processos de produção e recepção dos textos, a universalidade dos discursos políticos e suas consequências para a comunicação intercultural, em especial, a tradução. Por fim, Schäffner (2007) resgata os principais conceitos e autores dos Estudos da Tradução que abordaram, ao longo dos anos, questões como língua e poder, aspectos pragmáticos e a forma como são traduzidos, relação entre política e escolhas tradutórias e assim por diante.

Outro aspecto importante discutido no texto de Christina Schäffner é a predominância de alguns idiomas em detrimento de outros. Por exemplo, a autora menciona quais línguas e em quais direções (texto-fonte e texto-alvo) ocorre certa predominância de um idioma. Schäffner (2007) refere-se ao fato de o inglês ser considerado língua franca e ao poder dos Estados Unidos, alertando para as implicações políticas desse fato. Além disso, a autora discute, por exemplo, a tradução e a interpretação como atividades cotidianas em países multilíngues e cita o caso de vários países africanos. É evidente que a tradução nesses contextos não está livre de tensões, haja vista, por exemplo, o caso da Nigéria. De acordo com a autora,

A tradução e a interpretação ocorrem praticamente todos os dias em países bilíngues ou multilíngues, embora esse fenômeno ainda não tenha sido objeto de pesquisas substanciais. Feinauer (2004), por exemplo, comentou sobre iniciativas governamentais para traduzir textos de serviços de saúde para uma variedade de línguas étnicas na África do Sul. Em contraste com tais desenvolvimentos encorajadores, Kofoworola e Okoh (2005) explicam que as diversas visões de mundo e tradições culturais na Nigéria apresentam enormes problemas para a tradução. Conflitos políticos e desconfiança entre grupos étnicos são barreiras às atividades de tradução (SCHÄFFNER, 2007, p. 1394).

Em conformidade com as afirmações apresentadas por Schäffner (2007), observa-se que o termo "política e tradução" também se relaciona, de alguma forma, com iniciativas governamentais, já que a autora explicita a tradução de textos na área de saúde como uma alternativa para incluir a população do Sul da África pertencente a diferentes grupos étnicos. Nessa perspectiva, temos uma aproximação das ideias defendidas por Schäffner (2007) e Meylaerts (2010), na medida em que as autoras argumentam sobre a tradução como elemento das ações governamentais.

Meylaerts (2010), ao discutir sobre política de tradução, ressalta que, de forma restrita, o termo "política" poderia se referir à condução dos assuntos públicos e políticos administrados por um governo. Por outro lado, a autora destaca que, se examinarmos a concepção mais ampla de política, observamos que ela não está atrelada somente ao governo ou a agências governamentais, mas também a contextos institucionais, organizações internacionais como a União Europeia e a Organização das Nações Unidas, entre outras instituições.

Meylaerts (2010) nos mostra que o termo "política de tradução" é um guarda-chuva que abriga uma série de assuntos a serem dialogados e pesquisados, tais como: a formação de tradutores, as condições de produção e de recepção dos textos, a circulação das traduções por meio das editoras, o mercado de trabalho, as ideologias e estratégias adotadas no processo tradutório (que podem dar visibilidade ou não a determinada cultura), assim como os textos escolhidos para serem traduzidos e aqueles que ficam marginalizados perante os sistemas culturais.

Todos esses temas se constituem como centrais para as políticas de tradução e estão fortemente respaldados na interface dos Estudos

\footnotetext{
${ }^{4}$ Translation and interpreting occur practically on a daily basis in bilingual or multilingual countries, although this phenomenon has not yet seen substantive research. Feinauer (2004), for example, commented on government initiatives to translate health care texts into a variety of ethnic languages in South Africa. In contrast to such encouraging developments, Kofoworola and Okoh (2005) explain that the many different worldviews and cultural traditions in Nigeria pose huge problems for translation. Political conflicts and mistrust between ethnic groups are barriers to translation activities (SCHÄFFNER, 2007, p. 139).
} 
da Tradução com áreas como a Sociologia, a Antropologia, a Educação, os Direitos Humanos, a Filosofia, as Letras, a Linguística e a Literatura. Diante dessas possíveis articulações com diversas áreas, é esperado, evidentemente, que os diálogos sejam construídos a partir de diferentes perspectivas, o que afeta a implementação das políticas de tradução. Por exemplo, as ações governamentais criam e determinam um viés de políticas de tradução a serem adotadas pelas comunidades.

Por outro lado, as comunidades usuárias dos serviços de tradução e de interpretação podem oferecer pistas distintas sobre a construção de políticas de tradução e exigir ações voltadas para suas demandas, ou podem ocorrer conflitos entre as próprias comunidades, já que nem todas são contempladas pelas ações governamentais e assim por diante. Em contrapartida, o meio acadêmico pode elencar diferentes elementos para o desenho de políticas de tradução a partir de suas demandas, as quais se distinguem das demandas dos usuários dos serviços de tradução e de interpretação, das comunidades envolvidas, das ações governamentais e dos tradutores e intérpretes que atuam no mercado de trabalho.

Cada um desses grupos mencionados acena para diferentes reivindicações propícias à criação de políticas de tradução e, dependendo do país, podem se aproximar em maior ou menor grau de acordo com os interesses das partes. Embora as demandas sejam diferentes, não quer dizer que não possam estar interligadas de algum modo, caso seja uma decisão política e estratégica em prol de um determinado objetivo.

Decisões tomadas pelo Estado afetam o mercado de trabalho para tradutores e intérpretes. Em alguns casos, esses profissionais estão coagidos a trabalhar perante protocolos que proíbem um assunto, um tema ou uma escolha vocabular em determinados textos. Panda (2013) chama atenção para as forças ideológicas, podendo ser religiosas, políticas e socioculturais, que atuam por trás da tradução. O autor apresenta uma série de exemplos que mostram a atuação do Estado e o poder como "agentes" que exercem forças coercitivas sobre a tradução.

Determinados tipos de textos podem ter sua tradução proibida em função do teor informacional que carregam consigo, como aponta Panda: "O medo de divulgação de informações privadas ou pessoais de uma pessoa no poder pode causar uma proibição de qualquer mídia que comunique tais informações. Esse medo pode ser impulsionado por perda política e autoral por parte do partido

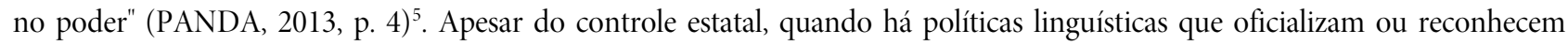
legalmente determinado idioma, a tradução pode colaborar para a expansão dessa língua. Em parte, essa linha de raciocínio é ratificada por Panda (2013). O autor exemplifica o caso da Índia, das políticas linguísticas e das políticas de tradução nos contextos multilíngues:

\begin{abstract}
Mas a Índia como país é tão heterogênea que dificilmente poderíamos imaginar que a fórmula das três línguas fosse um sucesso. Pessoas de muitos estados usam duas línguas - uma a oficial e outra sua própria língua materna, como, por exemplo, em Bihar (o hindi é a língua oficial e o maithili é a língua mãe da maioria das pessoas em Bihar). Houve uma divisão linguística dos estados indianos que deu poder ao respectivo governo do estado para promover e empoderar suas línguas, para que assim sejam liberados fundos para o desenvolvimento de materiais na língua - e a tradução é uma maneira fácil de concretizar esse objetivo. (PANDA, 2013, p. 6) ${ }^{6}$
\end{abstract}

Do mesmo modo que a tradução pode colaborar para a promoção e expansão das línguas reconhecidas legalmente pelo governo, torna-se fundamental uma postura crítica diante desse fato. É relevante considerarmos que algumas línguas foram reconhecidas, ao passo que outras, por inúmeras razões, deixaram de ser oficializadas, permanecendo invisíveis e à margem da sociedade. Esse fato tem desdobramentos importantes que merecem ser destacados. Uma tradução não ocorre de forma isolada em uma cultura. A seleção dos textos a serem traduzidos, os materiais que foram subsidiados financeiramente pelo governo revelam a intencionalidade

\footnotetext{
5 "The fear of disclosure of private or personal information of a man in power may cause a ban on any media that communicates it. This fear might be driven by a political and authorial loss on the part of the party in power" (PANDA, 2013, p 4).

${ }^{6}$ But India as a country is so heterogeneous that we could hardly imagine of realizing the three language formula a success. People of many states use two languages - one the official and the other their own mother-tongue, as for example in Bihar (Hindi as the official language and Maithili is the mother-tongue of most of the people in Bihar). There has been a division of Indian states linguistically which has given power to the respective state government to promote and empower their languages for which they release funds for developing materials in the language - and translation is an easy way of getting this objective concretized (PANDA, 2013, p.6).
} 
e a escolha de um determinado grupo social. Logo, tais entidades estatais têm um poder arrojado perante a sociedade. Estão localizadas em determinada época, em certa região geográfica e com fins específicos que afetam as obras que serão traduzidas. Assim, essas variáveis podem comprometer tanto o processo de tradução quanto o produto final, isto é, a tradução em si. Como resultado, há um impacto na forma como essas traduções serão acolhidas pelo público alvo.

Na maioria das vezes, os textos escolhidos para tradução são aqueles considerados canônicos pela sociedade, tais como obrasprimas, textos de maior prestígio e status social. Por outro lado, os textos não canônicos poderiam ser todos aqueles que ficam à margem dessa primeira categorização, isto é, literatura traduzida, panfletos, folhetins e outras publicações. Esse processo de seleção de alguns textos em detrimento de outros coloca em evidência as relações de poder existentes entre as culturas e comunidades étnicas que definem o que deve estar no centro e o que deve ficar na periferia do polissistema literário. Carvalho (2005, p. 30) afirma que Even-Zohar concebe as relações de poder entre “[...] os elementos dos sistemas através das imagens de centro e periferia, sendo o centro o lugar ocupado por aqueles que detêm maior poder dentro de um sistema e a periferia a região ocupada por elementos menos dominantes ou hegemônicos [...]".

É interessante observar que os conceitos de centro e periferia não necessariamente estão envolvidos com o desenvolvimento econômico dos países, mas emergem a partir da posição que ocupam nos sistemas socioculturais. Em alguns casos, o papel da tradução e da interpretação pode estar diretamente implicado com o direito internacional e com minorias linguísticas. É o caso de Núñez (2014), que investigou a tradução para minorias linguísticas com foco nas políticas de tradução no Reino Unido.

Em um primeiro momento, Núñez (2014) apresenta os conceitos de Estado, Línguas Oficiais e Minorias Linguísticas, argumentando a favor dos direitos linguísticos (a quem deve e como devem ser concedidos esses direitos), questionando se o debate sobre direitos linguísticos considera ou não a tradução. A perspectiva de direitos linguísticos adotada no texto de Núñez (2014) é a do direito internacional e, por isso, o autor ressalta a tradução como uma obrigação na garantia desses direitos.

Em um segundo momento, Núñez (2014) apresenta e discute o background linguístico no Reino Unido, detalhando as línguas oficiais e as minorias linguísticas de cada um de seus países. O autor explica como a tradução é encarada no Reino Unido e analisa como os governos locais estabeleceram diálogos promovendo ou não as políticas tradutórias. Núñez (2014) finaliza sua tese mostrando como ocorre a tradução nas esferas médicas e jurídicas no Reino Unido e propõe a tradução como meio de integração e acesso das minorias linguísticas:

A fim de permitir que aqueles posicionados como minorias linguísticas se integrem como parte da sociedade, vários níveis de acesso, participação e até mesmo reconhecimento têm de ser negociados. Em suma, dependendo de fatores contextuais, a tradução pode ser um importante meio para se alcançar maior inclusão ou integração de minorias linguísticas. E isso é tudo o que eu realmente queria dizer. (NÚÑ̃Z, 2014, p. 334) ${ }^{7}$

O argumento defendido por Núñez (2014) concebe a tradução como um meio para alcançar maior inclusão ou integração de minorias linguísticas, dialogando, também, com políticas de tradução que foram reconhecidas a partir de lutas das comunidades locais. Ou seja, trata-se de considerar não somente os direitos linguísticos pautados no âmbito do direito internacional, mas também as comunidades consideradas minorias linguísticas que resistem e lutam pela garantia de leis sobre línguas.

Até o momento, apresentamos uma contextualização sobre o uso dos termos “tradução e política" e "política de tradução”. Além disso, exemplificamos algumas situações em que o processo tradutório ou de interpretação é afetado por aspectos ideológicos, culturais, religiosos, zonas de conflito, entre outros, a fim de indagar como esses elementos são discutidos no Brasil. Por isso, na próxima seção, colocamos em questão algumas iniciativas sobre políticas de tradução e a conexão com políticas linguísticas em nosso país.

\footnotetext{
${ }^{7}$ In order to allow those positioned as linguistic minorities to integrate as part of the whole of society, varying levels of access, participation, and even recognition have to be negotiated. In short, depending on contextual factors, translation can be an important means to achieve greater inclusion or integration of linguistic minorities. And that is all I really wanted to say (NÚNEZ, 2014, p. 334).
} 


\section{POLÍTICAS DE TRADUÇÃO: ALGUMAS INICIATIVAS NO BRASIL}

No Brasil, o termo "política de tradução" tem sido utilizado de forma genérica, às vezes, para designar leis que tratam de determinada língua e mencionam a tradução ou a interpretação, como no caso das línguas de sinais, ou ainda para designar procedimentos e estratégias adotados na tradução de obras que abordam temas como estudos de gênero, colonialismo, tradução cultural, tradução literária entre outros. Aliás, algumas iniciativas recentes no Brasil buscam aproximar o campo das políticas linguísticas às políticas de tradução. Um exemplo disso pode ser observado na descrição do grupo de pesquisa Políticas Linguísticas Críticas, registrado na Universidade Federal de São Carlos, que agrega pesquisas sobre políticas de tradução.

A relação entre políticas linguísticas e políticas de tradução também é alvo de discussão nas comunidades que lutam pelo reconhecimento oficial de suas línguas e enfrentam resistências governamentais ou de diferentes grupos étnicos. Nesse contexto, as políticas de tradução podem ser consideradas como obrigação do Estado no provimento de serviços de tradução e interpretação para comunidades consideradas minorias linguísticas. É o caso das línguas de sinais, em especial, a Língua Brasileira de Sinais Libras. Santos e Zandamela (2016) mostraram que os movimentos políticos em torno das línguas de sinais (Libras e LSM - Língua de Sinais de Moçambique), a favor de seu reconhecimento como direito das comunidades surdas, afetaram diretamente as decisões sobre a tradução e a interpretação de línguas de sinais, tanto no Brasil quanto em Moçambique. O percurso desses movimentos políticos e de reconhecimento linguístico-cultural das línguas de sinais, na maioria das vezes, desdobrou-se em:

i. leis e resoluções que normatizam princípios linguístico-educacionais (como a língua deve ser nomeada, como deve ser ensinada, para quem e por quem deve ser ensinada, quais os lugares que deve ser ensinada);

ii. normativa e perfis de tradução e interpretação (a definição do profissional da tradução e da interpretação, a formação de tradutores e intérpretes, a definição de lugares de atuação para esses profissionais, normas e códigos de conduta);

iii. em recomendações ao poder público em relação ao uso e à difusão da Libras.

Em relação ao Brasil, esses elementos comentados anteriormente podem ser exemplificados com o caso da lei de Libras 10.436/2002 (BRASIL, 2002) e do decreto 5.626/2005 (BRASIL, 2005), que contribuíram com o desdobramento de uma série de políticas linguísticas voltadas à oferta de cursos de graduação para a formação de professores de língua de sinais ou formação de tradutores e intérpretes, além de contribuir com o incentivo das pesquisas sobre línguas de sinais nos níveis de mestrado e doutorado e com a ampliação de vagas para professores e tradutores-intérpretes nas universidades federais e privadas. Ou seja, todas essas decisões em torno da língua não se restringem apenas à língua em si, mas estendem-se também para as decisões em torno da tradução e da interpretação.

A mobilização das comunidades surdas a favor do reconhecimento da Libras é um caso típico que exemplifica a articulação entre políticas linguísticas e políticas de tradução. Como resultado disso, temos o aumento da indústria da língua e a expansão de novos mercados de trabalho para professores, tradutores e intérpretes etc. No entanto, essas conexões entre políticas linguísticas e políticas de tradução não devem ser tomadas de forma ingênua. Os conceitos de centro e periferia, tal como Even-Zohar os discute, e, além disso, o controle estatal, constituem-se como aspectos que merecem atenção. Políticas linguísticas e políticas de tradução não se resumem às leis (grifos nossos).

Quando há essa crença disseminada pelas diferentes entidades, sejam elas governamentais ou não, o risco de cair em uma emboscada é certeiro. Essa armadilha se alimenta da ideia equivocada de que bastariam as leis para institucionalizar a conquista de direitos, quando na verdade a lei proporciona um grau de letargia pouco explorado e debatido no meio acadêmico. Com isso, não estamos desmerecendo o importante papel desempenhado pelas leis, apenas alertamos para as implicações oriundas desse reconhecimento, que precisa constantemente ser revisado e reconfigurado conforme as demandas das comunidades linguísticas.

Outro risco proveniente do reconhecimento legal das línguas é a invisibilidade dos movimentos que continuam a resistência ao controle estatal e apresentam possíveis alternativas, as quais, na maioria das vezes, não são incorporadas aos documentos legais. Em virtude disso, alguns problemas podem ser observados com relação ao exercício profissional, por exemplo, de tradutores e intérpretes de Libras-Português. Se, por um lado, no decreto 5.626/2005, há recomendação para que a formação dos tradutores e 
intérpretes de Libras-Português seja em nível superior, por outro lado, a lei 12.319/2010, que reconhece e regulamenta a profissão do tradutor e intérprete desse par linguístico, delibera que o nível de formação seja o ensino médio. Esse descompasso legal traz consigo sérios problemas para o exercício profissional dos tradutores e intérpretes e tem sido alvo de constantes críticas por parte das entidades representativas e pelo meio acadêmico.

Ademais, as relações de poder estão nitidamente intricadas nas concepções e nos métodos que constituem as leis e resoluções. Por outro lado, considerando que políticas linguísticas não se reduzem às diretrizes legais, e levando em conta a falta de conexão entre políticas linguísticas e políticas de tradução, a ausência de um planejamento sistematizado e definidor de políticas de tradução para os tradutores e os intérpretes de Libras-Português é uma constante. É fundamental estar ciente que, ao mesmo tempo em que o governo e as comunidades que lutam por visibilidade e reconhecimento podem eleger determinadas línguas e ações a serem promovidas, outros idiomas acabam se tornando marginalizadas no âmbito social.

O ponto mencionado no parágrafo anterior também foi defendido por Panda (2013). O autor explica que nem sempre línguas de tradição oral são traduzidas na Índia, o que gera exclusão aos falantes dessas línguas. Segundo Panda (2013), banir ou acolher determinada língua é um ato que possui motivação política. Seja como uma política linguística que emerge das comunidades ou como uma obrigação legal, as políticas de tradução ocupam um papel central nas sociedades. O papel da tradução, os meios e os modos de produção e circulação, além da profissionalização dos tradutores e intérpretes para que estejam atentos a essas questões são alguns elementos que podem contribuir para elucidar o termo "políticas de tradução".

Por fim, é primordial que o elo entre políticas linguísticas e políticas de tradução tenha maior visibilidade em nosso país, pois os benefícios dessa conexão podem auxiliar ambos os campos. Não é recomendável que as políticas de tradução estejam desconectadas das políticas linguísticas, pois, em qualquer país, as decisões tomadas a respeito das línguas podem promover ou não as ações em torno da tradução. No Brasil, um exemplo que ilustra esse caso é o da Libras, pois as ações governamentais e a luta das comunidades surdas a favor do reconhecimento legal dessa língua propiciaram uma série de desdobramentos não somente para as comunidades surdas, mas também para os tradutores e os intérpretes de Libras-Português, influenciando, em especial, a formação desses profissionais.

\section{CONSIDERAÇÕES FINAIS}

A tradução ou a interpretação é um meio que pode ser utilizado para facilitar o acesso das comunidades consideradas minorias linguísticas às diferentes esferas sociais. No entanto, pouco tem sido investigado no meio acadêmico brasileiro sobre as conexões entre os campos de Políticas Linguísticas e Estudos da Tradução, especialmente, em relação à subárea políticas de tradução. Um panorama dessa falta de conexão pode ser observado nos espaços acadêmicos que hospedam essas discussões. Normalmente, as políticas linguísticas estão localizadas em Programas de Pós-Graduação em Linguística, e os Estudos da Tradução, em Programas de Pós-Graduação em Estudos da Tradução.

Por esse motivo, apresentamos neste ensaio um debate inicial sobre os termos "tradução e política" e "políticas de tradução", a fim de identificar alguns elementos importantes que perpassam a constituição dos dois termos. Em um segundo momento, resgatamos algumas iniciativas que podem ser tomadas como ponto de partida ao defendermos a conexão entre políticas linguísticas e políticas de tradução. Para ilustrar algumas dessas questões acionamos o caso da Libras, que explicita claramente políticas linguísticas voltadas à língua, às comunidades surdas e aos tradutores e intérpretes.

Por fim, acreditamos que este debate pode interessar pesquisadores em políticas linguísticas e políticas de tradução, assim como tradutores e intérpretes que lidam cotidianamente com desafios linguísticos, culturais e tradutórios. Se as forças dos diferentes envolvidos nesse processo de conexão forem somadas, a tendência é que novos caminhos passem a ser planejados, sistematizados e implementados nas políticas linguísticas das diversas comunidades brasileiras. 


\section{REFERÊNCIAS}

BHABHA. H.K. O local da cultura. Tradução: Myrian Ávila et al. 3. reimpressão/2005. Belo Horizonte: Ed. UFMG, 2005.

BAKER, M.; SALDANHA, G. (Org.). Routledge Encyclopedia of Translation Studies. London/ New York: Routledge, 2008.

Translation and conflict: a narrative account. London: Routledge, 2006a.

Translation and activism: emerging patterns of narrative community. The Massachusetts Review, v. 47, n. 3, p. 462-484, 2006b.

BRASIL. Decreto n 5.626, de 22 de dezembro de 2005. Regulamenta a Lei no 10.436, de 24 de abril de 2002, que dispõe sobre a Língua Brasileira de Sinais - Libras, e o art. 18 da Lei no 10.098, de 19 de dezembro de 2000. Diário Oficial da União, República Federativa do Brasil, Atos do Poder Executivo, Brasília, DF, 23 dez. 2005, nº 246, ano CXLII, Seção 1, p. 28-30.

. Lei no ${ }^{\circ}$ 10.436, de 24 de abril de 2002. Dispõe sobre a Língua Brasileira de Sinais - Libras e dá outras providências. Diário Oficial da União, República Federativa do Brasil, Atos do Poder Legislativo, Brasília, DF, 25 abr. 2002, nº 79, ano CXXXIX, Seção 1, p. 23.

. Lei n ${ }^{\circ} 12.319$, de 01 de setembro de 2010. Dispõe sobre a regulamentação da profissão de Tradutor e Intérprete da Língua Brasileira de Sinais - Libras. Diário Oficial da União, República Federativa do Brasil, Atos do Poder Legislativo, Brasília, DF, 2 set. 2010. № 169, ano CXXXIX, Seção 1, p. 43.

CARVALHO, C. A. A tradução para legendas: dos polissistemas à singularidade do tradutor. 2005. 160 f. Dissertação (Mestrado em Estudos da Linguagem) - Programa de Pós-Graduação em Letras, Pontifícia Universidade Católica do Rio de Janeiro, Rio de Janeiro, 2005.

HOLMES, J. S. The name and nature of translation studies [1972]. In: VENUTI, L. The Translation Studies Reader. Londres: Routledge, 2000. p.172-185.

JESUS, R. B. A interpretação médica para surdos: a atuação de intérpretes de LIBRAS/Português em contextos da saúde. TCC (Trabalho de Conclusão de Curso) - Centro de Comunicação e Expressão, Universidade Federal de Santa Catarina, Florianópolis, 2013. Disponível em: <https://repositorio.ufsc.br/handle/123456789/105420> Acesso em: 05 maio 2017.

MEYLAERTS, R. Translation policy. In: GAMBIER, Y., van DOORSLAER, L. Handbook of translation studies online (Ed.). Holanda: John Benjamins Publishing Company, 2010. p.163-168, 2010. Disponível em: $<$ http://www.benjamins.com/online/hts $>$. Acesso em: 5 jun. 2016.

MUNDAY, J. (Ed.). The Routledge companion to translation studies. London: Routledge, 2009.

NASCIMENTO, G. CTN. A (in) visibilidade do intérprete: a representação de Abed em Notas sobre Gaza. Tradterm, São Paulo. v. 27, p. 201-216, 2016.

NÚÑEZ, G. G. Translating for linguistic minorities: translation policy in the United Kingdom. 2014. 409f. Doctoral Thesis (PhD in Translation and Intercultural Studies) - Department of English and German Studies, Universitat Rovira i Virgili. Tarragona, Spain, 2014. 
PANDA, A. K. Politics and translation. The Criterion An International Journal in English, v. IV, issue II, 2013. p.1-7.

PÖCHHACKER, F. Introducing interpreting studies. London: Routledge, 2004.

PYM, A. Exploring translation studies. London and New York: Routledge, 2010.

QUEIROZ, M. Interpretação médica no Brasil. 2011. 134f. Dissertação (Mestrado em Estudos da Tradução) - Programa de PósGraduação em Estudos da Tradução, Universidade Federal de Santa Catarina, Florianópolis, 2011.

RODRIGUES, C. H. Da interpretação comunitária à interpretação de conferência: Desafios para formação de intérpretes de língua de sinais. In: CONGRESSO NACIONAL DE PESQUISA EM TRADUÇÃO E INTERPRETAÇÃO DE LÍNGUA DE SINAIS BRASILEIRA, 2., 2010, Florianópolis. Anais... Florianópolis: Universidade Federal de Santa Catarina, 2010. Disponível em: <http://www.congressotils.com.br/anais/anais2010/Carlos\%20Henrique\%20Rodrigues.pdf> Acesso em: 10 abr. 2017.

SANTOS, S. A. dos; ZANDAMELA, N. G. R. Políticas linguísticas e tradução-interpretação de línguas de sinais: aproximações entre Brasil e Moçambique. Working Papers em Linguística, Florianópolis, v. 16, n. 2, p. 101-123, dez. 2015. Disponível em: <https://periodicos.ufsc.br/index.php/workingpapers/article/view/1984-8420.2015v16n2p101>. Acesso em: 12 maio 2017.

SCHÄFFNER, C. Politics and translation. In: KUHIWCZAK, P.; LITTAU, K. (Ed.) A companion to translation studies - topics in translation. Clevedon: Multilingual Matters, 2007. p.134-147

TYMOCZKO, M. Enlarging translation, empowering translators. Manchester: St. Jerome, 2007.

VENUTI, L. The translation studies reader. London/New York: Routledge, 2000.

WADENSJÖ, C. Community Interpreting. In: BAKER, M. (Org.). Routledge encyclopedia of translation studies. Londres e Nova York: Routledge, 1998. p.33-37. 